\title{
TEM Identification of Phases in Metallic Pu-based Fuels
}

\author{
Assel Aitkaliyeva ${ }^{1}$, James W. Madden ${ }^{1}$, Cynthia A. Papesch ${ }^{1}$ \\ ${ }^{1 .}$ Idaho National Laboratory, Idaho Falls, USA
}

Metallic fuels are considered for application in advanced fast reactors because of their high burn-up, high fissile and fertile density capability, and high thermal conductivity with significant safety benefits [1]. Metallic fuels have several potential advantages, such as simple fabrication, robust performance, benign response to reactor transients, and relatively easy recycling using compact molten salt electrochemical processing. The uranium-plutonium-zirconium ( $\mathrm{U}-\mathrm{Pu}-\mathrm{Zr}$ ) alloys are considered to be one of the most promising metallic fuels. The addition of $\mathrm{Zr}$ in U-Pu matrix was sought to increase the melting temperature of U-Pu alloys and to enhance compatibility between the fuel and stainless-steel cladding by suppressing the interdiffusion of fuel and cladding constituents during steady-state reactor operations.

Phases formed in Pu-based systems have been previously experimentally investigated using thermal analysis techniques, X-ray diffraction (XRD), and wavelength and energy dispersive spectroscopy (EDX/WDX) in scanning electron microscopes (SEM) [2-4]. The issue associated with both XRD and SEM analyses is that both techniques are surface-based. In addition, spatial resolution, magnificationdependent sensitivity of EDX/SEM, and overlap between $U$ and Pu peaks in EDX results in questionable quantitative chemical analysis of Pu-based phases. To avoid such uncertainties, detailed structural and chemical composition analysis of phases and microstructure of $\mathrm{Pu}-\mathrm{Zr}$ and $\mathrm{U}-\mathrm{Pu}-\mathrm{Zr}$ fuels has been conducted in the transmission electron microscope (TEM). The high spatial resolution of TEM allowed characterization of individual matrix phases. Selected-area electron diffraction (SAED) using transmission electron microscopy provided important space-group information and lattice parameters of the phases formed in ternary $\mathrm{U}-\mathrm{Pu}-\mathrm{Zr}$ system.

Surface of the specimen was initially examined using EDX/WDX techniques in a JEOL JSM 7000F field emission SEM operated at accelerating voltage of $20 \mathrm{kV}$. SEM was used to examine the formed microstructure and determine the location of the phases of interest. To reduce charging in the SEM, a layer of Au coating was applied to the sample surface prior to the insertion into the instruments. Crosssectional specimens for transmission electron microscopy (TEM) were prepared in a FEI QUANTA 3D field emission gun (FEG) dual beam focused ion beam/scanning electron microscope (FIB/SEM) using a lift-out approach. Specimens for transmission electron microscopy were characterized in a FEI Tecnai TF30-FEG STwin TEM operated at $300 \mathrm{kV}$.

Figure 1 shows backscattering electron micrograph acquired from the U-Pu-Zr fuel. Several distinct phases were observed in the fuel. Initial SEM examination indicated formation of three phases in the fuel $-\mathrm{Zr}$ enriched globular inclusions, $\mathrm{U}$ and $\mathrm{Zr}$ enriched phase, and $\mathrm{U}, \mathrm{C}$, and $\mathrm{O}$ enriched matrix. SEM examination was followed by detailed TEM analysis. Implementation of a FIB instrument allowed for the preparation of cross-sectional TEM specimens from these transuranic samples. Multiple lamella containing features corresponding to different phases have been prepared to ensure a thorough and accurate identification of the phases formed in the alloy. Approximate lift-out locations in one area are identified with white rectangles in Fig. 1. An overview of the microstructure in one of the lift-outs is provided in Fig. 2. 
References:

[1] D. E. Burkes, R. E. Fielding, D. L. Porter, J. Nucl. Mater. 392, 158 (2009).

[2] M. Kurata, K. Nakamura, T. Ogata, J. Nucl. Mater. 294, 123 (2001).

[3] K. Nakamura et al, J. Nucl. Mater. 304, 63 (2002).

[4] Y. H. Sohn et al, J. Nucl. Mater. 279, 317 (2000).

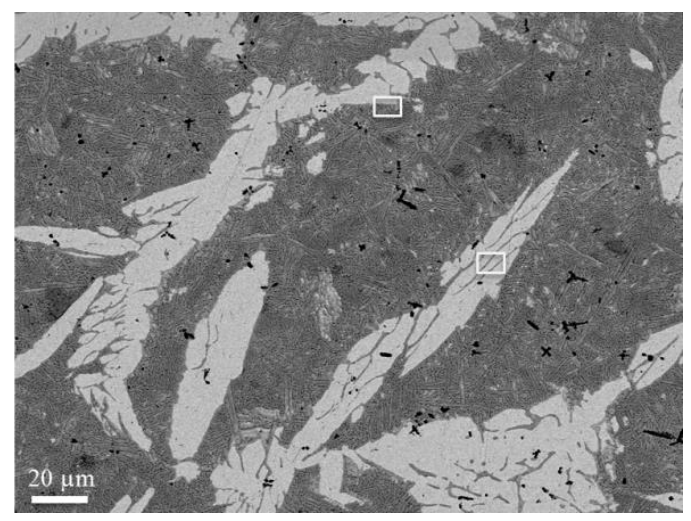

Figure 1. Backscattering electron (BSE) micrographs showing the microstructure of the U-Pu-Zr fuel. Two white rectangles identify positions of TEM lift-outs.


Figure 2. STEM micrographs of the cross-sectional specimen lifted-out from U-Pu-Zr fuel. 